\title{
7 FORMACIÓN PERMANENTE DEL PROFESORADO DE E.S.O.: DESAFÍOS DE UNA NUEVA ETAPA
}

Antonio Medina Rivilla

$U N E D$

\section{EDUCACIÓN SECUNDARIA, ETAPA COMPLEJA DEL SISTEMA EDUCATIVO}

El Sistema Educativo es la estructuración de los procesos educativos en coherencia con las demandas de los estudiantes y de la sociedad, acomodándose a sus exigencias cambiantes, pero manteniendo lo más representativo de los logros alcanzados en la misma.

Entre las etapas configuradoras del Sistema, la denominada Secundaria, por contraposición, quizás complementariedad, a la Primaria, se ha constituido en su fase Obligatoria como un espacio educativo generalizado y básico que han de cursar todas las personas, y cuya principal finalidad es capacitarlas y facilitarles las condiciones formativas adecuadas para comprender su mundo y lograr realizar en él su proyecto existencial en interacción con las demás, participando activamente en la mejora continua de él, aplicando los valores más coherentes con un mundo globalizado y con un especial respeto a la diversidad cultural de cada grupo e individuo.

Los Sistemas Educativos de los diversos países y, especialmente de los europeos, evidencian la complejidad de esta etapa, tanto por su diferenciación en el inicio de la misma, cada uno tiende a reencontrar su identidad 
situándola a los 11 , o a los 13 años, como por su relación con la anterior y posterior, especialmente en su compleja incardinación con la formación profesional.

La Educación Secundaria es la etapa que coincide con la evolución más difícil del ser humano, la adolescencia, que implica una crisis psicosomática y que requiere una atención adecuada para facilitar el desarrollo de la personalidad, desde su configuración singular en el marco familiar y contextual más amplio.

La etapa obligatoria requiere una atención adecuada en España, ya que su doble ciclo y su difícil incardinación, en no pocos casos, con los anteriores centros de Básica está impidiendo que adquiera su propia especificidad y disponga de los adecuados espacios y Centros. Las expectativas que ha generado como un ámbito de mayor nivel cultural para todas las personas de España está requiriendo de la Unión Europea tanto una mayor homologación con los restantes estados de la Unión, como una plena contextualización, constituyéndose en el desafío de las Administraciones Autonómicas y en la urgente adecuación a las demandas de microcontextos urbanos, periurbanos y comarcales que den a las instituciones de Educación Secundaria el reconocimiento social y cultural que se necesita para convertirlas en los Centros de desarrollo personal y social deseados.

La Educación Secundaria recupera el dominio de los aprendizajes básicos y la interiorización cultural de las dos etapas anteriores, Infantil y Primaria, dándoles un sentido más amplio en tres dimensiones: la académico-interdisciplinar, la intercultural y la axiológico-social, que hagan de esta etapa un espacio de plena consolidación del Sistema Educativo en relación con las expectativas de cada persona y de la sociedad.

La ESO, y su calidad instructivo-formativa para todos los estudiantes de 11 a 16 años, hasta 18 en función de su ecosistema familiar, personal y de desarrollo integral, requiere una reflexión acorde con este gran reto. Aún es más compleja la situación si la consideramos en su relación con el Bachillerato y la Formación Profesional como períodos de culminación de la actualización formativa de los estudiantes en su capacitación para el acceso a la Universidad y a las nuevas ocupaciones o profesiones.

La interrelación entre los dos niveles de Educación Secundaria es otro nuevo escollo que el Sistema ha de salvar, ya que la incorporación a las ocupaciones o al Bachillerato requiere no considerar, esencialmente, selectiva la etapa obligatoria, sino formativa y capacitadora para las siguientes, esperando la mejor formación de los estudiantes, acomodándose a sus expectativas y propiciando las bases de una educación integral, a la vez que se aspira a la mejor preparación intelectual, socio-afectiva y metodológica para encontrar respuestas a los complejos retos del futuro. 


\section{IDENTIDAD DE LA EDUCACIÓN SECUNDARIA OBLIGATORIA}

Esta etapa supone la adecuación del Sistema Educativo a las necesidades de todas las personas, especialmente de las que no van a continuar en otros niveles, esperando encontrar en esta etapa básica la mejor preparación para aprender a aprender, a innovar y a entender la complejidad de su mundo, si bien hemos de entender que la sociedad del conocimiento en la que nos encontramos requiere de las personas capacitadas la adquisición de hábitos, valores y métodos de auto y co-aprendizaje que las sitúen de modo interrogador ante sí mismas y las demás personas, ya que la "Educación Permanente" es una exigencia de nuestra sociedad y hemos de aspirar a dedicar una parte esencial de nuestro tiempo a actualizarnos y a disfrutar aprendiendo. Este aprendizaje tiene diferentes ámbitos: el estrictamente personal, el socio-laboral, el de ocio, el de participación social, el intelectual, etc... que ponen de manifiesto el gran desafío de la Educación Secundaria, concentrándose en dar a las personas el estímulo, los intereses y las expectativas para interesarse permanentemente por su formación y la búsqueda de ideas nuevas que mejoren su situación personal, ambiental y profesional.

La etapa, en cuanto básica y generalizada, ha de replantear sus prioridades instructivas, metodológicas y proyectivas, que representan la selección de los contenidos más representativos y con potencialidad formadora para que las personas se comprendan a sí mismas, entiendan su mundo y busquen las soluciones adecuadas a los ingentes problemas de una sociedad tecnologizada e interdependiente, pero muy necesitada de parámetros universales más rigurosos y solidarios, desde los que se incite a la responsabilidad compartida y a la colaboración, en la que el binomio deberes y derechos quede adecuadamente integrado en los proyectos y procesos de participación social.

La Educación Secundaria enfocará sus preferencias en el equilibrio entre la actualización y acomodación del saber académico y el pensamiento heurístico, facilitando a los estudiantes caminos, estilos y marcos desde los que entenderse a sí mismos y dar respuestas valiosas a una sociedad compleja y con emergentes focos de desigualdades, cuya vivenciación y soluciones han de depender de la asunción de los problemas por todas las personas y por la generación de actitudes adecuadas a la superación de los mismos.

Las señas de identidad de la nueva etapa son tanto las de universalización del Sistema a todas las personas, como su adecuación real a cada estudiante, equipo, socio-grupo y singular contexto familiar y sociocultural, en un nuevo marco autonómico, español, europeo y mundializado, que plantea a los estudiantes unos retos y unos procesos que por su inmediatez y novedad ponen en tela de juicio numerosas respuestas educativas del sistema anterior. 
Sin embargo, la singularidad de la etapa pasa tanto por los objetivos de la misma, los contenidos, como el nuevo espacio europeo, al que hemos de dar soluciones, sin dejar de atender al microcontexto del Centro, comarca y ciudades pero reencontrando su verdadero sentido.

Los estudiantes participan obligatoriamente en el Sistema, lo que plantea al profesorado que no todos viven con la misma motivación e interés el sentido de la etapa, pero tiene para el profesorado el gran aliciente de que durante al menos cuatro años o un lustro pueden contribuir al desarrollo humano y a la transformación global de los adolescentes del Centro; lo que en sí puede poner de manifiesto el desafío solidario e institucional del profesorado que trabaja en el mismo, quizás con el deseo de que al menos pueda permanecerse en la institución durante este cuatrienio para llevar a cabo los estudios evolutivos que implican el seguimiento del grupo de estudiantes en las tareas de tutoría, orientación educativa y mejora de la microsociedad escolar y de la comunidad educativa en general.

La nueva etapa es una oportunidad profesional con todos sus retos y exigencias, sirviendo al profesorado de Secundaria, en su múltiple complejidad cultural, como una realidad que requiere de la activa colaboración de los ecosistemas familiares, las Administraciones, las diversas instituciones y de un nuevo impulso de todas las posibles iniciativas, asociaciones y cuantas personas vivan la educación como la actividad más valiosa para la mejora integral de los individuos y la sociedad. Los equipos de docentes ante una nueva etapa obligatoria han de actualizar sus concepciones, sus ideas en torno a la misma, pero esencialmente sus opciones socio-educativas y su implicación profesional, individual y colaborativa, ya que no es sólo el Sistema el que está necesitado de la adaptación de estudiantes y docentes, sino que la transformación de aquél se ha de reflejar en la nueva Secundaria, ofreciendo a la sociedad una mentalidad, criterios y valores que demuestren su adecuación y necesidad para la mejora de los estudiantes y la sociedad.

\section{INNOVACIONES REALES DE LA EDUCACIÓN SECUNDARIA}

La ESO ha pretendido innovar su estilo de enseñanza-aprendizaje, su acercamiento a los estudiantes, el compromiso profesional y la organización de los Centros; sin embargo, aún faltan grandes esfuerzos para que, desde el profesorado a los estudiantes y desde las Administraciones Educativas a la práctica docente, sea una realidad la profunda transformación de esta etapa, con su identidad cuatrienal o lustro, atendiendo a las demandas y posibilidades de los estudiantes. Entre los desafíos que presenta la etapa señalamos los siguientes: 


\section{- Generalización de la Educación Secundaria a todas las personas en edad escolar.}

La Educación Secundaria es un nivel de ampliación del Sistema y capacitación de las personas para que logren un desarrollo cultural más intenso y consigan una mejor comprensión del mundo, de sí mismas y de las demandas concretas que le plantean las nuevas ocupaciones y una sociedad en permanente cambio.

La Educación Secundaria ha significado, en la pasada centuria, la etapa de preparación para la Universidad y el mundo del trabajo, estableciéndose una clara separación entre las personas que accedían a ella y la superaban y los que no podían cursar este nivel. Se establecía una diferencia que marcaba una mayor separación entre los jóvenes, en función de sus posibilidades para continuar en el Sistema. El avance de la Educación Secundaria para todas las personas no sólo supone una mayor cualificación y una más razonable redistribución y participación cultural, sino ante todo el compromiso personal por lograr una plenificación intelectual y afectiva más acorde con las demandas sociales y los desafíos de la sociedad del conocimiento.

Esta generalización requiere un esfuerzo del Sistema Educativo para atender a todas las personas en su singularidad y en sus específicas expectativas y necesidades formativas. La nueva etapa ha de retomar de la visión clásica de la Educación Secundaria el valor formativo de las áreas del currículum y la capacitación cultural y actitudinal, que contribuya a la formación integral de los estudiantes, pero ha de incorporar las innovaciones de la Educación Secundaria Obligatoria, que se perfila como el nivel más crítico del Sistema y más necesitado de una clara actualización del valor instructivo-formativo más clásico, para situarse en una mayor disponibilidad ante las demandas de cada estudiante y grupo humano, así como aportando las perspectivas en torno a un proceso de enseñanza-aprendizaje más creativo, ligado a la actualización cultural contextualizada, a la emergencia de la capacidad de aprender a aprender y al desarrollo de hábitos y estilos de vida cada vez más coherentes con los valores de interculturalidad, solidaridad, respeto al medio ambiente, tolerancia y apertura ante las diversas opciones en el planteamiento de los problemas.

\section{- Integración y diversidad educativa}

La Educación Secundaria para todas las personas representa un proceso de sensibilización y de búsqueda de las acciones educativas más pertinentes para todos los participantes. Entre las innovaciones de la etapa, señalamos el concepto de institución educativa abierta y esforzada en atender a todos los estudiantes, cualquiera que sean sus demandas y exigencias, replanteándose desde el propio Centro las adaptaciones curriculares y el 
sentido que el proyecto formativo de la institución ha de tener para llevar a cabo una visión de la escuela secundaria comprometida con todas las personas y sus demandas.

La escuela devuelve el protagonismo a la sociedad, al acoger en sus aulas a todos los estudiantes, cualesquiera que sean sus expectativas, intereses, capacidades, valores y formas de entender la realidad. Esta heterogeneidad, lejos de restar sentido y significado a la institución educativa, la convierte en un espacio de clara identidad social. La aceptación de personas iguales, pero afortunadamente diferentes, está unida a la construcción de un clima de empatía, diálogo y procesos de innovación permanente. Si se acepta esta igualdad y el derecho a formar parte de la comunidad educativa desde las diferencias, la nueva institución de Secundaria no podrá ser ni selectiva, ni restrictiva, sino cada vez más comprensiva y generosa con todas las demandas. Esta institución con grandes desafíos requiere más recursos, mejores medios y básicamente un profesorado implicado en este reto, conocedor de las perspectivas, modelos y estrategias coherentes con esta visión.

La atención creativa a los diferentes estudiantes requiere de un modelo intercultural que valore en sus justos términos las identidades culturales de cada grupo y persona y promueva la aceptación mutua, el desarrollo de un clima de tolerancia y la indagación compartida entre cuantos participan en el Centro y el aula.

El reconocimiento de las diferencias ha de entenderse en su perspectiva más amplia y compleja, ya que cada ser humano tiene sus capacidades y expectativas que hemos de estimar y construir conjuntamente en un espacio de comprensión y de apertura que haga posible que cada persona desempeñe óptimamente su proyecto de vida en colaboración con los demás y encuentre su identidad.

La integración educativa ha recalcado el énfasis en la atención a aquellos estudiantes extrañados anteriormente por el Sistema, casi recluidos en Centros distintos, para reconsiderar la metáfora de la escuela inclusiva (García Pastor, 1996) que define la institución educativa como la organización más adecuada para dar cabida y entidad formativa a todas las personas, demostrando su nivel de calidad en el proceso de implicación y solidaridad real con los estudiantes con necesidades educativas singulares.

Esta escuela de la apertura y de la igualdad requiere del profesorado una nueva capacidad de adaptación, reconocimiento y aceptación de las diferencias, que implica un trato acorde con las mismas en un clima de continuo reconocimiento de la dignidad y del esfuerzo que estos estudiantes llevan a cabo, a la vez que la instauración de un clima de búsqueda y colaboración generalizada, procurando que el profesorado tenga los medios y la asistencia de colegas que los apoyen en esta nueva demanda. 


\section{- Comprensividad de la etapa y sentido finalista}

La visión comprensiva de la escuela se ha consolidado como tesis diferente a la propuesta selectiva que acepta que las capacidades, intereses y rendimiento de los estudiantes son los que han de marcar las diferencias entre ellos, en vez de considerar la escuela como un espacio de vida, colaboración y participación en igualdad, reconociendo la multiculturalidad y la tolerancia, situando el énfasis en la igualdad dentro de la diferenciación.

La escuela, en general las instituciones educativas despiertan del letargo selectivo y configuran un marco socio-organizativo profundamente respetuoso con cada estudiante, pero consciente de la complejidad de todos los seres humanos; son estos seres humanos los que descubren su sentido y se dan cuenta, en la nueva sociedad "estructurada y pensada" para todas las personas, que el ser humano con todas sus limitaciones y posibilidades es capaz de aprender a aprender con los demás, a generar un verdadero espacio comunitario y a descubrir los valores más ligados al reconocimiento diferencial de las personas, pero trabajando desde un clima de profundo respeto, igualdad y avance personalizador.

La institución educativa, en la concepción comprensiva, disentida y discutible, como se evidencia en la acción educativa de los estados alemanes, no deja duda del esfuerzo que supone. El principio de la visión de la igualdad en el trato, derechos, deberes, valores, etc, de todos los estudiantes pone de manifiesto que la institución educativa ha de ser esencialmente configuradora de una visión y práctica formadora de todas las personas y poner en acción una acogida sin limitaciones a todos los estudiantes. Esta respuesta desde la educación es la que espera una sociedad basada en los principios y animada por un compromiso de transformación profunda de los seres humanos y de la comunidad en su conjunto.

La comprensividad de la institución educativa requiere de la identidad y culminación de esta etapa obligatoria, como un período con plena capacidad en sí misma, que tiene unas finalidades basadas en el reconocimiento diferente de los seres humanos, en el énfasis en la calidad de los procesos educativos, en un clima compartido de corresponsabilidad, en el logro continuo de interrelación de las etapas del Sistema y en la aceptación real del principio de la institución educativa creadora de vida y de búsqueda profunda de los plenos valores del ser humano, aspirando a alcanzar los procesos y resultados más plenamente instructivo-formativos, armonizando el logro de nuevas actitudes, capacidades y habilidades, con el dominio de las bases, conocimientos y hábitos que preparen con rigor a los estudiantes para participar solidariamente en la transformación y mejora de sí mismos y de toda la comunidad educativa.

La finalidad en sí misma y el reconocimiento de la identidad de esta etapa en el marco del Centro y del contexto en el que se encuentra abre grandes posibilidades al pluralismo y al compromiso intelectual, tanto de estudiantes 
como de docentes, que se verá reflejado en el Proyecto institucional del Centro. La razón de ser de la institución educativa es básicamente constituirse en el foco de cultura y en el espacio de vida sentimental, social e intercultural que capacite y dé sentido a todos sus integrantes para conectar con los valores más genuinos y la recuperación de las aportaciones académicas más reconocidas de la formación de la Educación Secundaria, procurando una compleja armonía entre la adquisición del saber interdisciplinar y el valor de los procedimientos científicos, con la incorporación de la multiculturalidad del contexto y esencialmente de cada estudiante, familia y grupos copartícipes en la institución de Educación Secundaria.

\section{- La interrelación de las áreas}

La Educación Secundaria estructurada en dos ciclos, de iniciación (12-13 años) y de consolidación (14-15 años), aporta una nueva estructura curricular que consiste en organizar las disciplinas más clásicas en conjuntos más interdisciplinares en torno a Áreas de Conocimiento. Así, los Decretos que desarrollan la LOGSE y las propuestas de enseñanza-aprendizaje de las Humanidades buscan una mayor cohesión e interrelación de los saberes en grandes ejes. Esta orientación curricular se ha completado mediante las denominadas Áreas Transversales, entendidas como nuevos campos propios de las sociedades evolucionadas, como sucede con la Educación Vial, Ambiental, etc, para lograr una participación social más racional, más que entendidas como síntesis disciplinares.

La Educación Secundaria necesita que el proyecto formativo del Centro asuma e interrelacione el conjunto de áreas al servicio de las finalidades formativas que han de lograrse en esta etapa en coherencia con los principios didácticos de individualización, integración, autonomía, colaboración, creatividad y significatividad del aprendizaje.

Esta necesidad de interrelación de los saberes y de búsqueda de los ejes de conocimiento y formación más adecuados a los estudiantes, comunidad educativa y entorno socio-comarcal-mundial en el que las personas del siglo XXI han de moverse, supone un gran reto a la concepción e integración curricular que puede sintetizarse en el diseño de un proyecto curricular de carácter integrado para los Centros de Secundaria en estrecha interrelación con las expectativas, problemas y demandas personales y socio-laborales de la realidad inmediata en la que vive cada estudiante y grupo de personas.

¿Cómo proceder para lograr esta integración de los elementos del currículum y especialmente de las áreas de conocimiento en un proyecto riguroso y compartido de naturaleza integrada?

La integración del saber plantea al profesorado la selección de núcleos temáticos representativos, en torno a los cuales se interrogan las aportaciones 
de las áreas y se configura el modo propio de elaborar el conocimiento en el Centro, implicando a todos los participantes en la búsqueda de la coherencia interna de los núcleos de estudio, la interrelación de los mismos, los procedimientos y métodos de indagación y enseñanza comunes. Lo que más orienta y da sentido compartido a la formación es la reflexión y el acuerdo en torno a los procesos y actividades de enseñanza, completados con la armonía en la identificación de las finalidades y objetivos formativos de la etapa, cuestionándonos para qué educamos a los adolescentes y cómo seleccionamos los más adecuados para la comunidad educativa y los estudiantes en particular.

El diálogo entre colegas es la base para crear currícula de naturaleza integradora, que sirvan a los intereses de los estudiantes y estimulen sus ilusiones por aprender a aprender y encontrar el sentido al proceso de interiorización y asimilación crítica de la cultura. Las clases desde esta orientación supondrán un esfuerzo de interrelación y de acuerdos compartidos entre colegas, pudiendo completarse esta visión integradora con el diseño de unidades didácticas, siguiendo el principio de estructuración del currículum en espiral. En el primer ciclo se determinarán, en equipo, tanto desde los respectivos departamentos como en interrelación departamental las Unidades Didácticas de cada curso y ciclo, las plenamente interdisciplinares e integradoras y los proyectos de incorporación de todas las áreas, creando una línea de indagación compartida entre docentes y estudiantes (Medina y Domínguez, 1995; Medina y col. 1999).

\section{- Adecuación al proceso de aprendizaje de cada estudiante}

La ESO se ha de caracterizar por transformar los Centros en organizaciones que aprenden y las clases en espacios de fomento del aprendizaje autónomo y colaborativo.

La actividad de enseñanza cobra todo su sentido cuando el estudiante es el verdadero protagonista y artífice de su aprendizaje, y encuentra en su proceso indagador la base de su formación como persona participante en el aula, en el Centro y en la comunidad educativa.

El aprendizaje que se propone en el marco de la Reforma pasada, LOGSE (1990), se circunscribe en exceso a la concepción constructivista, según la cual la acción del estudiante y su implicación en la misma es la base del aprendizaje, estrechamente dependiente de las ideas y organizadores de conocimiento anteriores, desde y más allá de las cuales se configura el nuevo saber.

Huber $(1997,1999)$ ha propuesto como perspectiva y base del aprendizaje el centrado en la actividad, autonomía y capacidad del estudiante para compartir con los demás, ya que la génesis del aprendizaje de cada sujeto se encuentra en la participación real que alcanza en el proceso y que se afianza cuando los resultados esperados coinciden con el esfuerzo dedicado. 
El aprendizaje es un proceso de mejora y de afianzamiento de los conceptos, habilidades y modos de pensar y actuar en el Centro, en el aula y en todas las situaciones de la existencia humana. Sin la colaboración de los estudiantes es imposible realizar el aprendizaje, pero esta colaboración requiere que el profesorado aprenda a despertarla e inquietarla, ya que su capacidad profesional se ve valorada, en parte, por su arte para interesar a los estudiantes en la calidad de las acciones que realizan.

Reconociendo la gran importancia y la representatividad que el constructivismo y el aprendizaje activo-autodescubridor tiene para los estudiantes y su formación, no podemos prescindir en la educación del aprendizaje por imitación e identificación y el de oposición-contraste. El aprendizaje por imitación se basa en el reconocimiento del docente como prototipo que presenta su visión sobre la realidad y que es capaz de mostrar justificadamente su visión del mundo y del área/proyecto interáreas que trabaja. De otra parte, y dada la necesidad de los estudiantes de crear su visión personal y su propia identidad por oposición a otras personas, hemos de entender que algunos estudiantes configuran su personalidad por antagonismo con el profesorado y explicitan numerosas conductas compulsivas ante las que es necesario mantener actitudes de tolerancia y apertura, así como generar, a pesar de ellas, un continuo clima de empatía y de interrelación estimuladora.

El estilo de enseñanza y el conjunto de acciones que ha de emprender el profesorado de ESO ha de caracterizarse por facilitar a los estudiantes un clima de búsqueda, participación y protagonismo corresponsable, sin olvidar las bases de identidad y de colaboración que cada docente ha de mostrar a los estudiantes para que libremente se sientan partícipes del proceso de enseñanza-aprendizaje.

La personalidad y la historia escolar de cada estudiante, equipo y de la clase como grupo, requiere una respuesta adecuada desde la práctica docente, incorporando a la cultura del aula la reflexión sobre los valores, actitudes y modos de actuar de la comunidad y de los estudiantes, a la vez que crear las bases para que puedan acceder a otros modos de vida y de comprensión de realidades más lejanas que les son accesibles bien por los medios de comunicación, las nuevas tecnologías o el conocimiento de personas que viven situaciones similares en otros países.

La Educación Secundaria ha planteado modelos de aprendizaje muy dependientes de la cultura escolar y menos proyectados a los problemas y preocupaciones de los propios estudiantes. Una visión más amplia del contexto formativo de los estudiantes requiere que cada grupo humano, y la escuela es básicamente un grupo intercultural, amplíe la concepción académica con la humanista y ésta con las necesidades de la ecología inmediata y mediata que preocupa a los estudiantes y a toda la comunidad con la que interactuamos. 


\section{- Programas de Garantía Social}

Esta propuesta innovadora puede trascender el valor innovador de la ESO y necesita ser considerada como una aportación complementaria para los estudiantes que no alcanzan los propósitos formativos del sistema y necesitan una atención adecuada para facilitarles el conocimiento de las ocupaciones y darles una nueva oportunidad para superar las limitaciones encontradas en la etapa.

La propuesta administrativa y la génesis de la misma se basa en el deseo expreso de apoyar a los estudiantes que no consiguen los propósitos y objetivos de la etapa para que encuentren en esta vía una mejor realización personal, social y ocupacional. Sin embargo, debemos aprovechar esta propuesta para situarla en la verdadera vía de actualización y de encuentro entre los estudiantes con necesidades de atención académica y singularizada y los docentes, que entienden que cada ámbito educativo es una situación fecunda para el óptimo desarrollo integral de los participantes, generando un marco de intercambio y de búsqueda plenificadora.

Los docentes y el Sistema han de diseñar los programas de atención a los estudiantes, a todos los estudiantes, pero con mayor dedicación a los que presentan dificultades en el aprendizaje, estableciendo desde él un verdadero espacio de integración social creadora, de responsabilidad compartida, de sentido de solidaridad y de esfuerzo por descubrir los nuevos problemas que estas personas han de encontrar en su relación con los demás, especialmente en el acceso al empleo, en la creación de ámbitos familiares y en las diferentes estrategias de interacción social que han de conocer para participar con éxito en su mundo.

Los programas que proponemos son propuestas formativas de naturaleza holística con base en la técnica de proyectos y que implican al mayor número de estudiantes y de docentes para lograr que el Centro de Educación Secundaria sea ante todo un espacio que crea conocimiento y se implica en las preocupaciones y desafíos reales de las personas y comunidades que con él se relacionan.

Los programas propician las garantías sociales y los procesos de desarrollo de las instituciones, cuando se plantean como espacios de diálogo unidos a problemas concretos y a proyectos que la comunidad en su conjunto ha de vivir y sentir como propios. Así, nos hemos de cuestionar en un marco socioacadémico abierto a las expectativas de la comunidad:

- ¿Qué problemas son los relevantes para esa comunidad?

- ¿Qué modelo de desarrollo sostenible se plantea?

- ¿Desde qué valores y claves ha de ampliarse el sentido social de la comunidad? 
- ¿Qué sentido tiene la institución educativa en este contexto?

- ¿Quiénes han de contribuir a resolver los problemas de desarrollo y de búsqueda que se plantean?, etc.

Las preguntas que podemos hacernos ante la necesidad de diseñar programas que sean una garantía social para jóvenes y personas mayores surgen de su realidad socio-laboral, en este caso de su experiencia socio-académica, en la que han de encontrar algunas respuestas y especialmente nuevos interrogantes, que el programa ha de conocer para buscar soluciones.

La garantía de un programa que desee atender ampliamente a los jóvenes que encuentran dificultades en el seguimiento del Sistema se encuentra tanto en la implicación del profesorado con el programa, como en la identidad que se logre de los estudiantes con el mismo. Esta identidad requiere apelar a la iniciativa de los jóvenes, a su ilusión para co-diseñar y adaptar, adaptándose al programa y sentar conjuntamente las bases de nuevas instituciones que aprenden en y desde la práctica, viviendo en colaboración las experiencias y extrayendo nuevas respuestas a los continuos interrogantes.

El programa ha de estar estrechamente unido a las líneas de desarrollo personal y ocupacional de la comarca/ciudad, sirviendo de reflexión y compromiso a todas las personas que deseen apoyarlo en el contexto y trabajar en las realidades y necesidades que conecten con las exigencias de la comunidad y de los jóvenes que se sienten poco integrados en la vida académica; así se atiende a sus limitaciones y se busca una respuesta apropiada a las personas implicadas, singularmente a las que viven desprotegidas en el Sistema y a sus familias y grupo social, suscitando su colaboración y trabajando el programa desde un marco socio-relacional esencialmente transformador y colaborativo.

\section{RETOS DE LA ETAPA OBLIGATORIA PARA EL PROFESORADO DE EDUCACIÓN SECUNDARIA}

La etapa supone para el profesorado un esfuerzo de adaptación derivado del sentido de la comprensividad y de la singularización del aprendizaje, ligado a la necesaria armonía entre una intercultura contextualizada y un mundo globalizado e interdependiente.

La etapa ha de conectar con los valores más representativos de un mundo en cambio y de continua actualización de conocimientos, pero que ha de mantener el valor más clásico del nivel Secundario: la capacitación de las personas para aprender autónoma y responsablemente la cultura de su tiempo e implicarse en la mejor organización de la sociedad. En este momento 
histórico lo urgente es prepararse para renovarla, descubrirla y transformarla permanentemente, entendiéndola en el marco del principio de la Educación Permanente y de la innovación participada de la sociedad, aportando una actitud comprometida y una fecunda capacidad indagadora.

Entre los interrogantes que ha de contemplar el profesorado destacamos: ¿qué aspectos y aportaciones del nivel de Educación Secundaria han de recuperarse en la nueva etapa, dada la generalización de este nivel para todas las personas? El docente, más que selectivo y creador de espacios de separación, ha de ser esencialmente comprensivo de todas las personas y contextos, logrando mejorar la vida académica.

La coherencia entre los dos ciclos de Secundaria, la continuidad adecuada con la Primaria y la configuración de la etapa en su globalidad, requiere del profesorado acordar un proyecto formativo institucional fundamentado, dialogado y desarrollado con rigor, constituyendo estos logros el principal cometido del profesorado, como co-responsable de la mejora del sistema e impulsor de una nueva conciencia de la comunidad educativa y promotor de las acciones reformistas de las Administraciones al servicio de la etapa.

La participación del profesorado en la transformación de la etapa tiene varios ámbitos, con desigual implicación y transformación en el aula y Centro, pero que requieren un compromiso socio-profesional demandando un marco legislativo promotor de la identidad, significación y proyección de este período educativo, llegando en su caso a desarrollar en el proyecto formativo del Centro las bases de la transformación integral del Sistema.

La creación de un espacio de Centro, con un enfoque socio-transformador implicado con el contexto inmediato y abierto a las necesidades globales de un mundo en interacción permanente, requiere que los diseños curriculares y las prácticas de enseñanza-aprendizaje sean coherentes con estas ideas y se promuevan desde un sistema metodológico integrador y enfocado con una visión holística del proyecto, en el que cada área y programación se vertebre en acciones formativas concretas, se interioricen y den sentido en el marco global de un espacio socio-geográfico en desarrollo sostenible.

La responsabilidad docente se amplia y supera las habituales tareas del aula y del Centro para diseñar programas más amplios adecuados al desarrollo sostenible, encontrando la respuesta adecuada al clima socio-participativo y de implicación más global del que supone el Centro y la comunidad educativa. Sin embargo, el profesorado de Educación Secundaria ha de atender prioritariamente la realidad formativa y plenificadora de cada estudiante, equipo y clase, en colaboración con todos los colegas, pero dando a su trabajo una visión más comprensiva y holística, armonizando las necesidades inmediatas de su microcontexto con las demandas de la ciudad y comarca, espacio de extensión social en el que ha de actuar, sin cuya referencia se disminuye tanto el enfoque socio-laboral, como el sentido de la 
educación, actividad emergente de un futuro creador y de unas prácticas significativas.

¿Qué respuesta personal e institucional ha de dar el profesorado y los claustros?

Cada docente ha de considerar su situación, nivel de identidad profesional y exigencias que para él comporta la etapa, procurando suscribirlas y explicitarlas en un mapa representativo de la vida profesional y de los retos del futuro, pero no aisladamente, sino en el ámbito del Centro, la comunidad y marco socio-transformador (ciudad-comarca-autonomía-Europa-intercultura-mundo) en el que ha de vivir y del que ha de co-responsabilizarse. Esta micro, meso y macro proyección de la Educación Secundaria da su razón de ser y responde a las expectativas que la sociedad ha puesto en ella, como base de la mejora global del Sistema y de las personas.

\section{LA EDUCACIÓN SECUNDARIA: PERSPECTIVAS Y FINALIDADES}

La Educación Secundaria ha sido considerada como el nivel educativo más incidente en la totalidad de la población de un país, aunque no siempre ha sido considerado como finalista y autodeterminado, sino propedéutico para la capacitación de los jóvenes que acceden a otros niveles del Sistema Educativo.

¿Qué perspectiva se mantiene en la legislación vigente? Se tiende a dar prioridad a la adecuación de la etapa obligatoria a todas las personas participantes en el sistema, especialmente se considera que todos los adolescentes tienen el derecho y el deber de cursar la fase obligatoria. Esta fase pretende aplicar el principio de igualdad de oportunidades y facilitar a todas las personas el acceso a la educación básica, sintetizada en la adquisición de actitudes favorables hacia el aprendizaje.

La Educación Secundaria plantea, entre otras finalidades, la capacitación de las personas para entender su mundo y participar activamente en la interiorización de la cultura y en la transformación de su realidad, preparándose para incorporarse creadoramente a la sociedad y a la vida activa, buscando fundamentalmente:

- Capacitarles en el conocimiento y defensa de sus derechos y en el cumplimiento de los deberes.

- Educar a los estudiantes en el principio de igualdad de derechos entre diversas personas de distinto género, evitando toda discriminación y respeto a las diversas culturas. 
- Fomentar hábitos democráticos para construir una sociedad más participativa, responsable y solidaria.

- Asumir y construir los valores, destrezas, habilidades y conocimientos que orienten la formación de los jóvenes para la mejora continua de sí mismos y de la sociedad.

- Estimar e interiorizar las creencias, actitudes, sentimientos básicos, patrimonio cultural, etc, eligiendo las opciones que mejor desarrollen integralmente a las personas.

- Formar a los estudiantes en la búsqueda de valores y en el logro de actitudes de autonomía y responsabilidad.

- Preparar a los estudiantes en el conocimiento y estimación positiva de un medio ecológicamente sostenible y cuidado.

- Iniciar una apertura permanente hacia otras perspectivas sobre las profesiones, valores y las culturas.

Además de estos propósitos característicos de la Educación Secundaria, se ha de recuperar el valor más histórico-formativo de esta etapa, como impulsora del conocimiento, de actitudes y habilidades de las personas, que suponen la preparación de los responsables futuros como principales emprendedores y coordinadores de las instituciones.

La Educación Secundaria ha mantenido el valor del conocimiento académico y el sentido de la etapa preparatoria para una mayor intervención social. Se capacita a los estudiantes para comprender la cultura y reelaborarla desde una participación intelectual más creativa. Esta exigencia de madurez cultural ha de renovarse en la Educación Secundaria y valorar el encuentro entre la intercultura de las familias y el proyecto cultural del centro.

La adaptación a cada estudiante ha de completarse con la adecuación e interiorización de la cultura académica, dándole un proceso de actualización permanente y de capacitación de los estudiantes como responsables de su propia formación. Aunque consideramos la relatividad del conocimiento, su continua evolución y su significado provisional, sin embargo se mantienen algunos elementos esenciales en el contenido a estudiar;

- Los conceptos básicos que configuran el saber general de las disciplinas.

- Los procedimientos seguidos en las diversas disciplinas para comprender y avanzar en el conocimiento.

- La visión global de las aportaciones de las diversas disciplinas orientadas desde el proceso de elaboración del saber científico, artístico y tecnológico. 
Este proceso de configuración de la cultura requiere profundizar en los aspectos comunes y valorar la evolución de los conocimientos, destacando lo más valioso y permanente de las disciplinas y del saber científico, a la vez que replanteando los cambios adecuados en el estudio del saber académico.

\section{DERECHO Y RESPONSABILIDAD DE LA ACTUALIZACIÓN PROFESIONAL DE LOS DOCENTES}

La actualización se concibe en la LOGSE como un derecho y un deber del profesorado, configurando la doble implicación de los docentes, en su necesidad personal de anticiparse a las demandas de la Educación Secundaria y en la oportunidad de sentirse participantes de una nueva etapa que plantea la respuesta ilusionada ante los nuevos retos.

Desde el derecho reconocido a la formación, se considera que los/as educadores/as han de encontrar en la Administración, en las instituciones y en los Centros la respuesta adecuada para hacer realidad este reconocimiento.

El derecho requiere que cada docente lo asuma y ejerza; así desde la mejora de las condiciones de trabajo se ha de controlar el nivel de estrés valorando la amplitud de tareas, los procesos de cambio y la sensibilidad ante los continuos problemas de enseñanza-aprendizaje. El ejercicio del derecho a la realización profesional está unido a la existencia de oportunidades temporales y reales para configurar tanto una línea de actualización profesional singularizada, como un programa de desarrollo institucional en colaboración con todos los colegas.

El derecho representa para el profesorado una fecunda oportunidad de reflexión y valoración de las opciones concretas de conocimiento y de búsqueda de actualización y solución de los problemas que tiene planteados el Sistema Educativo, así como de las posibilidades que una nueva etapa necesita para la apertura y su mejora global. La formación habría de ser percibida por el profesorado como la actividad más adecuada para entender y avanzar el conocimiento profesional y la práctica formativa creadora.

La contrapartida del derecho, como oportunidad satisfactoria, la encontramos en el deber de formarse, entendido como obligación moral reclamada a su vez por el derecho de los estudiantes de poder ser atendidos y enseñados por los docentes más preparados y sensibilizados con su tarea. La educación es en sí la capacitación y la actividad social que más posibilidades de mejora propicia al conjunto de la sociedad, especialmente la que representa un modo nuevo de superar el carácter selectivo de la etapa anterior, y se considera 
como la más adecuada para hacer realidad el principio de igualdad de oportunidades.

¿Qué visión del deber y del derecho puede asociarse a la Educación Secundaria? Aquella que libere al docente de angustia y de control, situándolo en un espacio de armonía consigo mismo y de búsqueda en colaboración permanente con estudiantes y colegas. La acción educativa y el proceso de enseñanza-aprendizaje, por su propia naturaleza, necesitan de un sentido profundo y clarificador, a la vez que un elevado nivel de identidad con la tarea que se realiza. Esta tarea es compleja y muy difícil de asumir, siendo necesaria la reflexión, superación y colaboración en la misma. El profesorado amplía su horizonte profesional al pensar en los desafíos de la nueva etapa, planteándose las respuestas más acordes con la integración de los saberes y la planificación de las personas realizando un compromiso profundo con la investigación de y en la etapa.

\section{MODELO DE ACTUALIZACIÓN DOCENTE QUE PROPONEMOS PARA EL PROFESORADO DE EDUCACIÓN SECUNDARIA}

Los modelos de formación del profesorado han sido tan abundantes como las perspectivas y concepciones que en torno a la enseñanza se han generado.

Desde estas perspectivas se destaca el autodesarrollo profesional, el codesarrollo colaborativo y el desarrollo institucional implicado en el Centro. La formación permanente ha de estar estrechamente ligada a las siguientes posibilidades:

- Desarrollo del conocimiento profesional desde la práctica.

- Formación en colaboración con los colegas.

- Compromiso con la mejora personal e institucional.

- Reflexión indagadora de la docencia.

- Aportación de saber desde la investigación compartida en el aula y Centro.

Entre los numerosos procesos de construcción del saber profesional, hemos de destacar la reflexión en colaboración desde la práctica educativa y la aplicación de visiones y perspectivas teóricas que la enriquezcan y amplíen, valorándolas en interacción con los colegas.

La formación se plantea como un camino riguroso para compartir ante los docentes y la comunidad educativa el sentido, los sentimientos y los valores en los que apoyamos nuestra concepción y práctica educativa. La 
formación permanente requiere cuestionarse su génesis y las razones desde las que se ha de plantear, a la vez que hemos de encontrar un proceso transformador que proporcione a cada docente un estilo continuo de mejora y satisfacción profesional, comprendiendo las múltiples limitaciones para responder a la complejidad de las tareas que la Educación Secundaria Obligatoria aporta y requiere. Entre las aportaciones que hemos seleccionado para facilitar la formación del profesorado destacamos:

\section{Co-desarrollo profesional colaborativo (institucional)}

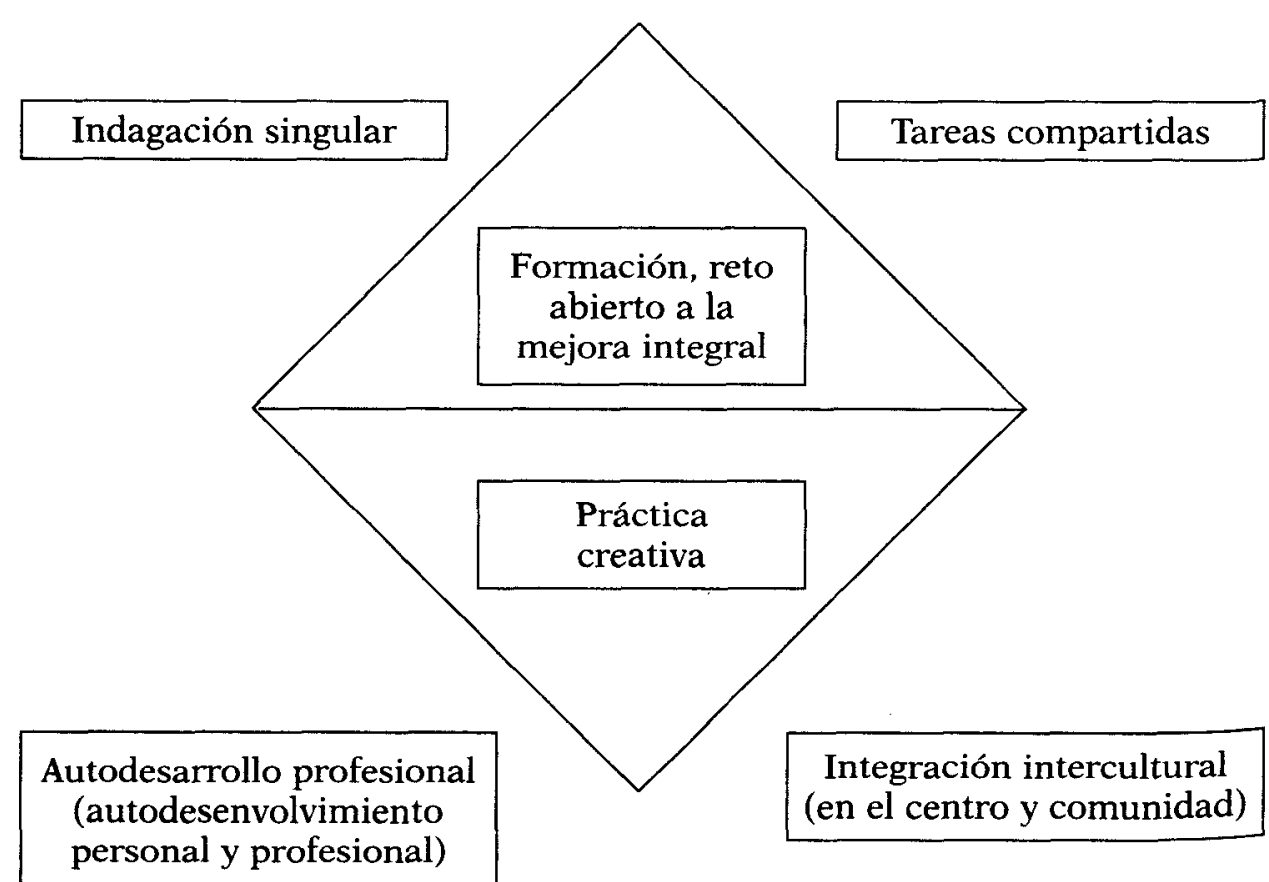

\section{DESAFÍOS DE LA ETAPA}

- Obligatoriedad

- Comprensividad

- Individualización

- Integración

- Propedéutica transformadora, etc. 
La capacitación y la vivenciación de la identidad profesional en Educación Secundaria requiere de la integración de dos modos de elaborar conocimiento: autodesenvolvimiento y co-desarrollo colaborativo, en el micro y meso contexto intercultural del Centro y de la comunidad educativa, proyectada en marcos comarcales, urbanos y autonómicos con implicación planetaria.

Incorporamos en esta propuesta la aportación de la comprensión e intervención holística que implica entender la formación en todas las dimensiones, al menos las personales, institucionales, socio-comunitarias y proyectivas, y en todos los entornos de Centro, departamento, ciclo y aula, armonizando la complejidad y amplitud de la formación con la urgencia de atender las demandas inmediatas de cada estudiante en el microcontexto del aula, en interacción con los demás compañeros y en el marco de su familia y la comunidad educativa.

Esta concepción de la formación implica una visión y repercusión globalizada, dando nuevos enfoques a la tarea y al proceso de auto y co-formación, revisando el proceso de avance autónomo y profesionalizador, atendiendo al constante intercambio y transformación de la institución desde las aportaciones de todos los participantes, realizando la actualización profesional en el mayor número de aspectos, pero propiciando que los implicados vivan su realidad en interacción con distintos enfoques culturales.

El modelo de formación es de naturaleza holística, ya que considera al docente como el principal creador de cultura en interacción con los colegas y la comunidad, reflexionando sobre el mayor número de procesos y dimensiones que implican una acción educativa transformadora ante un nuevo espacio europeo y un mundo en gran interdependencia.

La formación del profesional de la Educación Secundaria es la actividad más necesaria para comprender los cambios y situarse ante los mismos con una mentalidad de apertura y de anticipación a los nuevos problemas. Formarse es aprender a situarse creadoramente ante las perspectivas y demandas que la sociedad y el Sistema Educativo plantea al profesorado, aportando su visión actualizada del sentido y significado de la etapa obligatoria para atender a todas las personas del Estado.

El modelo de auto y co-desarrollo profesional desde el análisis y transformación de la práctica se fundamenta en la realidad del Centro y de las aulas, en el intercambio creativo con los colegas, como base para aprender a aprender en y desde la acción doçente, aplicando la metodología narrativo-interpretativa, el diálogo entre colegas y el criterio de referencia valorativa de algunas de las teorías más representativas de la enseñanza, como proceso y práctica socio-interactiva.

El modelo pretende armonizar el autoconocimiento de las concepciones e ideas personales de la enseñanza con el conocimiento profesional compartido 
entre los participantes, configurando un entorno de reflexión y de apoyo entre colegas, a la vez que de crítica abierta para la mejora del Centro como institución que aprende desde el diálogo creativo en colaboración.

\section{LA FORMACIÓN PERSONALIZADA: AUTODESARROLLO PROFESIONAL}

La formación es prioritariamente una decisión de cada docente que le facilita la adquisición de un estilo docente y las bases para diseñar su trayectoria de desarrollo profesional. Entre las numerosas líneas de actualización docente, destaca la que se apoya en la reflexión creadora y en la confianza personal por delimitar y dar sentido a la línea de perfeccionamiento autónomo. El autoconcepto profesional surge del convencimiento propio y de la práctica transformadora, que reclaman una actitud y unas bases para aprender a aprender, para indagar y sentirse protagonistas de la vivenciación personal y autónoma. ¿En qué basamos el autodesarrollo profesional? En la confianza en la capacidad de cada docente para asumir la formación como la base para la mejora de la educación y la consecución de las finalidades de la etapa.

Medina y Domínguez $(1997,1999)$ hemos propuesto como núcleo de la práctica indagadora y de su reflexión continua el autoanálisis de las experiencias docentes más representativas que han incidido positivamente en la educación de los estudiantes y en la actualización profesional. Esta descripción comprensiva de la acción educativa, de su sentido y de la implicación en el autodesarrollo personal y docente se ha constatado como una línea fecunda de construcción de conocimiento didáctico y de saber formativo.

En otro trabajo (Medina, 1996) hemos propuesto la perspectiva autobiográfica y la narración comprensiva de las acciones docentes como una base fundamentada para avanzar en la capacitación del profesorado y en el entendimiento de los procesos educativos que llevamos a cabo. La mejora profesional es un proceso que requiere del interesado una actitud sincera de apertura y asimilación creativa de nuevos modelos y prácticas de enseñanzaaprendizaje, difícilmente asumibles si no se dan algunos requisitos para entender las vivencias y los proyectos personales. Entre éstos se destaca el deseo manifiesto de emerger las teorías implícitas, las imágenes que mantenemos sobre la enseñanza, los procesos seguidos en la práctica educativa y la metodología heurístico-didáctica aplicada.

El autodesarrollo sitúa a cada docente en el responsable y principal protagonista de su línea de actualización profesional. Sin embargo, la autonomía necesaria para avanzar en este proceso se ha de ampliar y proyectar en 
el marco del intercambio colaborativo y del interpensamiento compartido entre colegas mediante la reflexión en el ámbito de la institución y en el diálogo entre el claustro y los equipos de departamento y ciclo (Medina y Domínguez, 1997).

El proceso de mejora de la profesión requiere de una adecuada síntesis entre la autonomía reflexiva y la comprensión empática de las decisiones docentes de los colegas. El autodesarrollo se plantea como una línea estimativo-valorativa de la propia práctica, a la vez que de plena confianza en el avance del modo peculiar de entender la realidad educativa.

Autodesarrollarse requiere actitudes y concepciones coherentes con este desafío, ya que la acción formativa es una práctica de conocimiento y actuación sinérgicas, pero básicamente de avance y mejora continua. La decisión de mejorar profesionalmente es connatural a todas las personas que realizan una actividad, quizás para los que han elegido la educación de otras personas esta práctica es aún más arriesgada y necesita ser entendida en toda su amplitud.

¿En qué aspectos cabe comprender y valorar positivamente el autodesarrollo profesional? En todos aquellos que atañen a la actividad educativa en general y a los contextos escolares y no escolares en los que ha de verse reflejada la calidad de esta práctica transformadora. Quizás es la naturaleza de la acción educativa y su potencialidad la que ha de ser comprendida en todas sus dimensiones, y cada docente ha de actuar como generador de saber y de nuevos modos creadores del proceso de enseñanza-aprendizaje.

El autodesarrollo profesional se apoya en la capacidad indagadora y en el dominio de la metodología adecuada para realizar una práctica educativa creadora de nueva cultura y de implicación con las diferentes personas y grupos.

El autodesarrollo continuo del profesorado tiene su base en la reflexión creadora desde la práctica y en la validación de experiencias plenamente formativas, en las que la indagación y la estimación de su sentido, proyección y significado queden suficientemente explicitadas. El autodesarrollo es un proceso de afianzamiento y búsqueda de la línea de avance profesional que cada docente considera necesaria desde su autorreflexión y la aportación de sus colegas. Autoformarse es básicamente realizarse y dar continuo significado a la acción educativa, reflejada en un modo argumentado de llevar a cabo el proceso de enseñanza-aprendizaje, de mejorar la escuela en su globalidad y de participar en la transformación permanente de la comunidad educativa y de los entornos socio-comarcales y urbanos en los que se actúa.

El autodesarrollo se basa en la capacidad de cada docente para identificar los puntos fuertes y débiles de su práctica educativa y tomar las decisiones que estime más adecuadas en el Centro, en los contextos de formación y en las múltiples situaciones de creación de saber, para lograr una 
actualización profesional acorde con sus expectativas, los problemas de la acción educativa y las necesidades del instituto como organización que aprende.

\section{TRABAJO EN EQUIPO: COLABORACIÓN COMPARTIDA}

Las expectativas y necesidades detectadas en la autorreflexión profesionalizadora se han de ampliar con las demandas demostradas de la institución educativa y de los entornos comarcales y ciudadanos, incorporando los procesos de la educación intercultural con proyección planetaria y dando respuesta justificada a los problemas y expectativas del entorno inmediato en el que ha de participar cada docente desarrollando un currículum comarcal integrador.

La formación en el marco de la colaboración entre colegas y la comunidad educativa reconoce dos modalidades especialmente valiosas: la formación en el Centro educativo y la construcción del conocimiento profesional en equipo. Estas dos modalidades coinciden con la visión más amplia del desarrollo organizativo de las instituciones, pero su foco es el profesorado como generador de la línea compartida de afianzamiento profesional.

Hemos de seleccionar la visión más clásica del trabajo en equipo del profesorado en torno a una tarea esencial, pero orientado desde el principio de la colaboración, como proceso indagador compartido que evidencia un fuerte compromiso con la institución y la transformación de la sociedad en general y singularmente de la comunidad educativa. El proceso de aprender a ser y realizarse como profesional requiere de la sincera y fecunda colaboración entre los participantes en el Centro, estudiantes, padres-madres, personal de servicios, etc, a la vez que es imprescindible emerger el trabajo educativo que asumen como responsables del Centro.

El trabajo en equipo se basa tanto en la aportación de la dinámica de grupos como en la elección justificada del proyecto o programa más valioso que la institución educativa ha de construir, o bien la elección justificada del conjunto de tareas más representativas que, desde los diferentes órganos colegiados del Centro han de asumirse desde el ciclo, el departamento o el equipo directivo, detectando los aspectos más adecuados para ser mejorados. El diseño de estos planes, desde una finalidad formativa y su aplicación creadora, realizados desde la metodología del trabajo en equipo, puede ser la modalidad formativa más valiosa que hemos de llevar a cabo para lograr el desarrollo profesional del profesorado en el Centro de Educación Secundaria.

Este proyecto de mejora educativa ha de tener como vértice innovador la co-reflexión participativa del profesorado y la búsqueda del discurso y 
metodología más adecuados para capacitarlo y generar un conocimiento profesional riguroso, comprometiéndose en la mejora y transformación de la comunidad escolar y del entorno.

¿En qué basamos y cómo realizamos el trabajo en equipo orientado por el principio de la colaboración?

El trabajo en equipo desde la perspectiva colaborativa es un proceso de aportación y participación de todos sus componentes para culminar la tarea propuesta. La tarea que se autoproponen los participantes consiste en resolver aquellos problemas que impiden el desarrollo de la institución educativa, la mejor formación de estudiantes y docentes y la emergencia de una cultura innovadora y solidaria con la sociedad. El trabajo en equipo surge de la realidad problemática de la escuela y las instituciones educativas en general, que requieren el esfuerzo aunado y conjunto de todos los docentes para superar estas limitaciones. El equipo de la escuela, departamento, ciclo y aula ha de plantear al inicio del curso el conjunto de actividades y planes de trabajo que se van a realizar con la mayor implicación posible de todos sus participantes. El trabajo en equipo ha de contribuir a enfocar con éxito las principales tareas, respetando la autonomía creativa de cada participante, pero evidenciando que la superación de las dificultades que plantea la nueva etapa depende de la capacidad de los docentes para tomar decisiones en común, desarrollar un discurso empático y colaborativo, configurar procesos de liderazgo participativos, incrementar la comunicación y apoyar la solución compartida de los conflictos, llevando a cabo cada una de estas acciones en coherencia con el principio de colaboración.

La acción colaborativa da un nuevo sentido al trabajo en equipo, ya que la elección de las tareas, la realización de las mismas y la valoración de su calidad formativa se alcanzan desde el acuerdo y la búsqueda en común de los principales logros para mejorar la práctica educativa, incrementando las bases de una cultura coherente con el desarrollo profesional de los
docentes.

La colaboración orienta el trabajo en equipo, tanto en la selección de los proyectos como en su aplicación, logrando un estilo de intercambio, acercamiento y responsabilidad compartida. La vivenciación e identidad del profederado con la cultura de colaboración les sitúa en un proceso de búsqueda y de compromiso que convierte las actividades del equipo, en sí mismas, en potencialidad formadora para cuantos intervienen en ella.

La metodología que ha de conocerse para realizar el trabajo en equipo la ta proceso de colaboración se basa en el diálogo y en la realización de la tarea desde el esfuerzo, la disponibilidad y la armonía entre el pensamiento y la acción. La exigencia de la colaboración es más que la reciproránd en el desempeño de las tareas de los miembros del grupo, configurándose como la óptima participación y satisfacción en la cooperación de 
las actividades entre todos los docentes. Esta satisfacción participativa lleva a reconocer el esfuerzo y la aportación sincera de cada componente, sin que estén necesariamente investidos de la urgencia manifiesta de resultados concretos. Sin embargo, el mayor alcance de la sensibilidad colaboradora es la aportación rigurosa y bien fundamentada de ideas, concepciones y modos de realizar la formación en el Centro y de conseguir que cada educador/a sea el/la que alcance su propio espacio de desarrollo profesional, tanto en beneficio de la institución en su conjunto, como de todas y cada una de las personas que la forman. Este esfuerzo de solidaridad compartida no renuncia a alcanzar las mejores cotas de calidad de la concepción y práctica educativa, pero destaca que hemos de aportar un estilo de plena responsabilidad cooperativa.

\section{INDAGACIÓN DESDE LA PRÁCTICA: CO-DESARROLLO INSTITUCIONAL Y PROFESIONAL}

La formación permanente del profesorado está estrechamente ligada a la construcción del conocimiento profesional, a su integración creativa en el Centro y a la transformación global del contexto social y comarcal en el que participa.

El conocimiento profesional depende del proceso de reflexión y mejora de la práctica, ya que, sin una experiencia profunda sobre el propio trabajo y sin comprender las claves de la evolución de la misma, es impensable que se produzca la elaboración de un saber profesional.

¿Qué tipo de práctica configura el desarrollo profesional? La que se constituye desde la indagación rigurosa y la creatividad del profesorado, avanzando con una visión renovada como el principal generador de la educación de los estudiantes. La reflexión crea conocimiento y da sentido a la práctica cuando se anticipa a las decisiones y se sitúa como la interrogación permanente, poniendo en tela de juicio tanto los procesos didácticos como sus resultados.

La práctica por la práctica puede convertirse en una pesada losa que impida el cambio, viéndose el profesorado ceñido a la rutina, a lo conocido, y careciendo de un marco teórico y de argumentos bien fundamentados para plantear mejoras. ¿Qué acciones han de posibilitar la mejora profesional? Las que se apoyen en una práctica creadora y se basen en una concepción teórica que dé razones y actuaciones coherentes con el pensamiento didáctico y con concepciones de la enseñanza que integren la práctica artística con una fundamentación científica y apliquen modos de transformar la realidad orientados por la tecnología, como teoría normativa de la acción profesional. 
La práctica aprovecha las innovaciones tecnológicas, con valoración crítica de su génesis y repercusiones, dado el impacto de la cultura actual y de su incidencia en los valores y en los modos de avanzar el conocimiento.

El profesorado de Educación Secundaria ante esta nueva etapa dispone de valiosas experiencias profesionales, pero necesariamente ha de adaptarlas a la visión y proyección de los saberes formativos, de la metodología y de las finalidades de la nueva etapa, optando por aprender de la reflexión de su enseñanza y de ampliar la validez del saber disciplinar a otros modelos y proyectos de formación cuya base es la metáfora de "aprender a aprender", "aprender a descubrir" y "aprender a innovar", que sitúa a los docentes como los más representativos creadores de situaciones de enseñanza que seleccionan y acomodan los conceptos y valores disciplinares a las demandas de la sociedad y de los estudiantes.

La práctica formativa requiere entenderse y desarrollarse en el marco de la institución escolar y darle a cada docente la oportunidad adecuada para que se cuestione su práctica, la reoriente y comparta reflexivamente con los colegas.

¿Cómo plantear la práctica en el marco institucional para que se transforme en la base de la formación permanente del profesorado? La práctica ha de ser esencialmente indagadora y de radical engarce con las vivencias y experiencias más innovadoras, se ha de asumir desde un compromiso sincero con los valores y actitudes que proporcionen una cultura escolar de cambios justificados, de espacios de búsqueda en común y de planteamientos creadores.

Un Centro implicado en la educación como base esencial para todas las personas requiere ser percibido y valorado como un espacio de apertura y de indagación continua, ya que la educación es básicamente actualización, configuración y formación continua, incrementada desde los proyectos globales y llevada a cabo con una perspectiva holística e integradora, incorporando a cada estudiante como el protagonista de su propia mejora.

La cultura alcanza el sentido de vivencia compartida cuando desde la práctica se promueve un sentido pleno de colegialidad, de superación de conflictos y de construcción de una línea vertebradora del saber y del hacer en interacción con todos los compañeros y compañeras.

\section{DESARROLLO PROFESIONAL DESDE LA FORMACIÓN DE LOS ESTUDIANTES}

La mejora profesional del docente está estrechamente ligada a la de los estudiantes. El proceso de interacción con los estudiantes y la tarea educativa 
con ellos es, probablemente, una de las bases más pertinentes para autorreconocernos como docentes y avanzar en el desarrollo profesional.

La interacción con los estudiantes nos forma desde el diálogo, el contraste, la crítica y la creación en común de las situaciones que nos permiten avanzar como personas y dar respuesta a la multitud de interrogantes que nos plantean.

¿Cómo plantear el diálogo con los estudiantes como una de las perspectivas más fructíferas para aprender a ser docentes? Entre los procesos de avance profesional destacamos los que generamos con los colegas, los que descubrimos en intercambio con los expertos e investigaciones y, especialmente, los que desarrollamos en interacción con los estudiantes. Cada estudiante, en su proceso singularizado de aprender, se muestra ante el docente como un innovador interlocutor, que le demanda una reflexión y una actualización didáctica continua, tanto para conocerle y respetarle, como para sentar las bases del proceso interactivo, como realidad primera de las vivencias más significativas que las situaciones educativas nos plantean.

¿Qué acciones capacitan más al profesorado en su interacción con los estudiantes? Entre las tareas que facilitan y dan valor al proceso de enseñanza-aprendizaje hemos de destacar las siguientes:

- Presentar de la información de manera motivadora y capacitar a los estudiantes para que se impliquen en los problemas de su entorno.

- Anticipar las situaciones más complejas de enseñanza-aprendizaje y trabajarlas desde el mayor número de dimensiones posibles, invitando a cada estudiante a formular sus proyectos y a entenderlos en toda su complejidad.

- Entender el aprendizaje como la actividad más relevante de los sujetos, especialmente la adquisición de los conceptos y procesos básicos en los que se sustentan los aprendizajes posteriores.

El diseño de las programaciones con la participación de algunos estudiantes, equipos y clases descubre al profesorado una base para crear un estilo narrativo y amplio de su realidad, de su entorno y, sin duda, de su significado profesional. La reflexión y la explicitación continua de las claves instructivas desde las que se mueve cada educador/a y las decisiones que toma ante cada estudiante, sirven de eje para realizar la mejora profesional, aportando innumerables datos que le sirven en el complejo proceso de enseñanza-aprendizaje.

¿Qué decisiones puede tomar el profesorado en interacción con los estudiantes para mejorar su capacidad formativa? Son muy numerosas las situaciones educativas que facilitan al profesorado su desarrollo profesional, pero singularmente implica asumir decisiones que posibiliten configurar cada 
aula como un espacio de indagación, de reflexión compartida y de apertura al saber. Las aulas son espacios creadores de valores, actitudes y modos de proceder. Así, cuanto mayor es la implicación de cada docente en este modo de compartir y de avanzar en el saber y hacer educativo, la realización profesional será mayor.

Proponerse el desarrollo profesional desde el diálogo y trabajo con los estudiantes implica establecer en el aula la cultura de la reflexión, creatividad e indagación continua, que evita que se trabaje desde la rutina o la reproducción permanente, avanzando continuamente en la búsqueda fecunda y el conocimiento de los procesos de interrogación. Una práctica innovadora integrará a los estudiantes en el autoaprendizaje y en la solución de problemas, ligando el avance en los conceptos y métodos básicos con la mejor vivencia de la realidad y de la relación entre ésta y el conocimiento.

La capacidad profesional del docente se asienta en su interacción con los estudiantes y en la emergencia de una cultura y gestión de aula de vivenciación, satisfacción y desarrollo compartido, que estimula a cada persona y equipo a sentirse en la clase como un espacio valorado, entendiendo el saber como el proceso de creación de conocimiento.

El profesorado de ESO puede encontrar, en la complejidad y desafíos de cada aula y ciclo, un espacio de avance creador y de afianzamiento calculado, ya que en esta difícil etapa el profesorado puede descubrir nuevos retos para afianzar la capacidad de solución de problemas y de desarrollo profesional.

\section{INTERDEPENDENCIA ENTRE LA FORMACIÓN Y LA MEJORA DE LA ACCIÓN DOCENTE}

La formación tiene una prioridad esencial que es capacitar al profesorado para realizar con dedicación y profesionalidad la tarea educativa. Los/las educadores/as son conscientes de la complejidad de la acción docente y de la necesidad de comprenderla en toda su amplitud e integrar la reflexión personal con los hallazgos del trabajo en equipo entre colegas.

La acción docente es la práctica más característica del proceso formativo, mediante la cual se configurà la educación de los estudiantes y se da sentido a la institución escolar. Los programas de actualización profesional destacan la importancia de preparar al profesorado para que reflexione sobre su docencia, la valore y tome las decisiones más pertinentes para desarrollarse como educador/a y cree las bases para que los estudiantes aprendan a aprender y se impliquen como protagonistas de su propia formación. La formación para 
entender mejor la tarea instructiva ha de atender a todos los procesos y cambios que afectan al contexto escolar, la comunidad educativa, las motivaciones y expectativas de los estudiantes, la representatividad del saber, los procesos comunicativos, la orientación global del proceso educativo, etc, pero, en esta amplitud de aspectos formativos que la acción docente ha de atender, ocupa un lugar relevante la interacción socio-comunicativa con los estudiantes, el clima del aula y la naturaleza del proceso instructivo, en cuanto sintetizador del saber, ser y aprender del conjunto de conceptos y métodos que caracterizan un campo de conocimiento, trabajando los valores y sentimientos más apropiados para emerger actitudes coherentes con el modelo de persona y sociedad que deseamos alcanzar.

\section{EXPECTATIVAS Y EXIGENCIAS DEL PROFESORADO: ESPACIOS DE INDAGACIÓN Y ADAPTACIÓN DE LA FORMACIÓN}

La formación permanente del profesorado de ESO ha de partir de las expectativas, anhelos y experiencias sentidas por el profesorado en el marco de las comunidades, de la sociedad en general y de las necesidades del Sistema Educativo y de los docentes. La formación permanente es "el proceso de reconstrucción continua del saber profesional adecuado para responder a las demandas de los estudiantes, las instituciones, la sociedad y el reto de desarrollo personal del docente, viviendo ética y comprometidamente la tarea educativa" (Informe de la Profesión Docente, INCE, p. 51). Si, como se subraya en este Informe, la formación inicial ha de incidir en el afianzamiento de la identidad profesional, los conocimientos necesarios para ejercer la docencia, la acción tutorial, y participar con implicación en la cultura del Centro, la ejercitación práctica y la capacitación creadora en el primer año de la docencia, hemos de plantear si se han actualizado adecuadamente las principales dimensiones docentes para configurar el conocimiento profesional desde la acción en el centro y en el aula.

La formación permanente del profesorado habrá de incidir en mejorar la "identidad profesional", dadas las claves de una etapa compleja y de proyección en todas las personas.

La identidad está relacionada con la percepción positiva que cada docente tiene de su trabajo y de las tareas prioritarias que ha de asumir. El citado informe evidencia que lo que más valora el profesorado es el sentido de servicio a la sociedad que ha de tener su trabajo y su proyección en la formación académica de la juventud. La identidad se asocia al sentido altruista y de dedicación que ha de caracterizar esta profesión, unido al compromiso de búsqueda y continua ilusión por mejorar. La identidad profesional depende 
de la autoimagen, del desarrollo y reconocimiento social de la tarea y del sociogrupo del Centro y la comunidad con los que interactúa. ¿Qué programas de formación mejoran la autoimagen, la capacidad perceptiva, las condiciones socio-profesionales y la autoestima? Se da como superada la capacidad para actuar profesionalmente y poseer una personalidad equilibrada, empática y sana. Sin embargo, la profesión docente, como otras de fuerte implicación axiológico-existencial, requiere un gran esfuerzo de reflexión y serenidad, ya que la acción formativa es una práctica transformadora que sólo puede comunicarse desde un clima y plano de coherencia y sinceridad entre el pensamiento y la acción, la teorización y la práctica creativa.

La etapa de ESO está siendo desempeñada mayoritariamente, y en el futuro íntegramente, por docentes con el título de Licenciatura, sin embargo se han consolidado los dos ciclos separadamente como situación de transición, que se está prolongando en exceso. Así, los docentes del período de Educación Básica y de Primaria, que actualmente vienen atendiendo al primer ciclo, generalmente son maestros con licenciatura. Estos docentes evidencian, en el estudio que citamos, un mayor grado de identidad con la nueva etapa que otros profesionales de enseñanza media que se sienten más identificados con la etapa post-obligatoria; asimismo los docentes que desempeñaban la Formación Profesional viven un período de adaptación con mayor sintonía.

El programa de formación de docentes que propicie un mejor proceso de identidad y que sirva al profesorado para elevar su autoimagen y autoestima será una aportación decisiva para la mayor satisfacción profesional y la consolidación de la Reforma Educativa. El nuevo estatus de Profesorado de Educación Secundaria, aunque manteniendo las situaciones administrativas de agregado y catedrático, en proceso de transición, ha generado en los docentes de la clásica enseñanza media más desencanto que ilusión, sin duda comprensible. Sin embargo, hemos de configurar un proceso de adaptación y de reconocimiento del estatus de este profesorado sin que genere discriminación para otras culturas docentes, integradas en la nueva organización de profesorado de Educación Secundaria.

La formación para la mejora del desarrollo profesional ha de partir de la autoestima personal y de una imagen positiva como docente; esta autoimagen se va actualizando y afianzando en la medida en que se vive la tarea docente como una práctica transformadora y de plena realización. Este logro innovador difícilmente se alcanza sin la reflexión acerca de las posibilidades de la acción educativa y sin los apoyos intracentro y extracentro. Los programas que podamos diseñar para promover la mejora de la identidad profesional han de contar con el compromiso real de las Administraciones Públicas para estimular el reconocimiento del esfuerzo y dedicación profesional y la colaboración entre colegas para desarrollar la práctica educativa en un clima de cooperación, empatía y apoyo mutuo, con la participación de la comunidad educativa en su globalidad. 
La identidad se consolida desde la satisfacción, el entendimiento entre colegas y la aceptación de los estudiantes, a la vez que reflexionando serenamente sobre la tarea educativa y profundizando en su sentido y comprensión, viviéndola en interacción empática y tolerando las diversas concepciones, prácticas y expectativas de la realidad.

La segunda dimensión es la que aglutina el saber profesional propiamente dicho centrado en la calidad del proceso de enseñanza-aprendiaje, que ha de ser entendido y trabajado desde la perspectiva institucional-colaborativa, con especial valoración de la coherencia entre la concepción y el trabajo del aula y la propuesta global del proyecto del Centro como oferta cultural fundamentada.

La formación permanente en esta dimensión ha sido la más desarrollada en cursos, seminarios, proyectos de innovación, actividades de indagación, etc. La construcción del conocimiento requerido para realizar la enseñanza como una actividad creadora de pensamiento y transformadora de la realidad social requiere ser estudiada e investigada desde la colaboración del mayor número de participantes y vivida como una experiencia radicalmente profesional.

$\mathrm{El}$ informe del INCE recoge en las páginas 52 y siguientes los aspectos más atendidos en los anteriores programas de formación y en los previstos para el próximo año. De nuevo se insiste en armonizar las necesidades de la implantación de la Reforma con el desarrollo de las competencias y capacidades profesionales para atender tanto las expectativas y necesidades del profesorado, como las exigencias de una toma de conciencia institucional para colaborar activamente con los Centros como espacios de profesionalización y con las necesidades de mejora de la comunidad escolar en su conjunto, armonizando las necesidades de actualización en la Didáctica de las Áreas y de la etapa con las tareas de orientación escolar, tutoría, atención a la diversidad y formación para la cultura del aprendizaje activo y la creación de iniciativas en y más allá de los empleos actuales.

Los programas, de manera más precisa, los cursos y seminarios de formación, han valorado tanto las necesidades de desarrollo profesional como las expectativas de los estudiantes, asimismo se ha focalizado la tarea formativa de las diversas instituciones en:

Mejorar la selección, organización y secuenciación de los contenidos de enseñanza-aprendizaje, las actividades y los ejes transversales seguidos de situaciones formativas que atienden a la formación tutorial, orientación, diversidad educativa, seguidos de la capacitación para diseñar "actividades" coherentes con la capacitación de los estudiantes y la evaluación de los mismos.

Los cursos orientados a desarrollar la capacidad reflexiva de los docentes son los menos frecuentes, quizás por la incidencia de esta capacitación en la 
autonomía profesional. Los docentes que más se han implicado en su formación han sido los que superan los cincuenta años, evidenciando su interés por actualizarse.

La formación para la mejora de la práctica docente en el aula, ciclo, departamento y Centro ha de atender tanto a la calidad de su diseño en el marco del centro, como en su aplicación en equipo en el departamento y en el ciclo, configurándose como un proceso y un ámbito de permanente mejora profesional. La práctica es la vivencia reflexiva que aglutina la fundamentación teórica con la construcción del saber práctico y garantiza las decisiones que continuamente se toman en la institución educativa.

¿Qué propuestas son las más adecuadas para realizar una formación del profesorado desde la mejora reflexiva de la práctica? Las que apuestan por el protagonismo y la iniciativa docente para construir su conocimiento profesional y avanzar en los procesos de búsqueda y transformación continua de la acción docente, apoyada en criterios de colegialidad, apertura e interrelación entre los participantes, incorporando al claustro y a la comunidad educativa a la reflexión sobre el sentido creador y orientador de la educación.

La formación ha de atender a la capacidad para diseñar e integrar los proyectos culturales de la comunidad educativa como planes innovadores de los Centros, presentados en una síntesis representativa de la visión cultural del claustro que sirve de marco a las programaciones de ciclo, departamento y aula, insistiendo en la selección de las actitudes y valores como la principal referencia del proyecto cultural del Centro, estructurando todo en torno a los principios de individualización, integración, socialización, creatividad, autonomía e interdisciplinariedad, situando el proyecto en coherencia con las expectativas y necesidades de los estudiantes y el profesorado.

Los contenidos de la formación del profesorado emergerán tanto de las necesidades de actualización de los docentes, como de las exigencias del Sistema Educativo y de la institución educativa en particular, sensibilizándose con la visión de una escuela abierta a las exigencias de la comunidad y de las personas en ella implicada. El informe aludido selecciona los siguientes principios, procedimientos y estrategias que el profesorado considera más relevantes para su actualización profesional en ESO (p. 56):

- Diagnóstico y comprensión de los conocimientos previos del alumnado.

- Atención singularizada y aplicación del principio de integración educativa.

- Aplicación de la transversalidad de las Áreas e interdisciplinariedad de los contenidos.

- Orientación a los estudiantes para integrar y aplicar los contenidos aprendidos. 
- Utilización de medios innovadores en la enseñanza.

- Personalización de los valores por el alumnado y logro de comportamientos coherentes con ellos.

- Desarrollo de la curiosidad, la creatividad, espíritu de diálogo y escucha atenta y crítica de las argumentaciones.

- Adquisición de hábitos, actitudes y capacidad de esfuerzo que mejore los procesos de aprendizaje.

- Generar estilos indagadores de enseñanza que propicien el aprendizaje activo, autónomo y colaborativo de los estudiantes, mediante culturas que apoyen la formación como la mejora permanente de la capacidad reflexiva y la toma de decisiones desde la práctica.

La formación ante las demandas de la nueva etapa han de tener en cuenta las tareas docentes más representativas (entre ellas el proyecto de colaboración en el Centro), el dominio de la enseñanza del área, la capacidad para diseñar la enseñanza y motivar a los estudiantes, a la vez que la proyección de la Educación Secundaria en la vida de los estudiantes y en la mejora de la comunidad.

El profesorado entrevistado en numerosas mesas redondas se hacía las siguientes preguntas:

- ¿Cómo compaginar la formación permanente con la atención a las exigencias laborales habituales?

- ¿En qué reside el valor profesional y la mejora de la capacitación de los docentes?

- ¿Qué aportan los programas de formación a la actualización personal y socio-laboral del profesorado?

La respuesta a estos interrogantes marcará la potencialidad y repercusión de las líneas de formación en el desarrollo profesional de los docentes y contribuirá a dar solución a los problemas y reticencias que la aplicación de la ESO pueda encontrar.

Los contenidos que se explicitan en las mesas redondas de diálogo con el profesorado son, prioritariamente, los siguientes:

- Conocimiento de las características de los estudiantes y del contexto del centro.

- Conocimiento de las disciplinas en cuanto objeto de enseñanza.

- Dominio de opciones metodológicas.

- Conocimiento de nuevas formas para motivar a los estudiantes. 
- Actualización y dominio de nuevas tecnologías.

- Construcción de la Didáctica del Área y de la Práctica instructivo-formativa.

- Desarrollo de actitudes y valoración de la cultura de la colaboración y el trabajo en equipo.

- Interiorización del sentido profesional y funcional de los departamentos, ciclos y comisiones.

- Iniciación y desarrollo de métodos y procesos de indagación, evaluación e investigación.

- Afianzamiento del conocimiento práctico, desde la reflexión teóricoindagadora.

Los contenidos de formación han de emerger de la reflexión profunda acerca de la línea de desarrollo profesional que desea plantearse cada docente y afianzar en equipo la cultura de colaboración para diseñar y aplicar las actividades de formación más coherentes con los deseos de los claustros, las necesidades de la comunidad y los entornos comarcales, autonómicos y nacionales y avanzar en el respeto a la singularidad creadora de cada docente.

La formación en la dimensión de la enseñanza y de la práctica educativa en general surge de la indagación de su sentido, proyección y posibilidades, y se afianza en la búsqueda permanente del modelo y representatividad de la educación, de la etapa de Secundaria y de la cultura de la institución que hemos de contribuir a mejorar como participantes comprometidos con una nueva visión y un proceso cada vez más riguroso de proyección socio-laboral y planetaria. Medina y Domínguez (1998), y Medina (en prensa) hemos pretendido dar sentido intercultural a la formación del profesorado y cuestionar la orientación, fundamentación, modalidades y proyección de la formación del profesorado de Educación Secundaria en una sociedad del conocimiento, en el marco europeo, pero con pretensión de colaboración con otros ámbitos y grupos humanos.

La práctica de la enseñanza y el trabajo en equipo del profesorado, como dimensiones constitutivas de la formación permanente, son las bases de la reflexión, la construcción del conocimiento práctico y las claves para afianzar el desarrollo profesional. La práctica en sí misma puede contribuir a mejorar al profesional, pero ha de vivirse como experiencia indagadora e innovadora si deseamos aportar un proceso riguroso que incremente el saber didáctico. La práctica es garantía de mejora de la enseñanza cuando se conceptualiza y explicita en interacción con los estudiantes y algunos colegas, volviendo a situarla y comprenderla en el mayor número de dimensiones. La práctica es creadora de saber y propiciadora de mayor identidad profesional cuando es valorada desde su significado y proyección, siendo entendida como la evidencia de teoría y la emergencia de nuevos modos de conocer y 
estimar la riqueza de la educación alcanzada por los estudiantes y los participantes en el Centro. El avance del saber didáctico en Educación Secundaria vendrá fundamentado desde el proceso y el diálogo fecundo entre el profesorado, que se replantea continuamente su saber y su acción en las aulas, y los investigadores que lleven a cabo con ellos programas de co-formación indagadora, diseñando sus finalidades, contenidos, modalidades y principales actividades de desarrollo profesional, a la vez que aplicando modelos de evaluación que evidencien la potencialidad formativa del programa, reflejada en la inmediata satisfacción y mejora del profesorado y en la mediata repercusión en la transformación del Centro, en el proceso de enseñanzaaprendizaje y en la instrucción formadora de los estudiantes.

La práctica autorreflexiva se ha de integrar en la línea de autodesarrollo profesional que cada educador/a se proponga, a la vez que se inserte en un programa más amplio desde el que dar sentido y oportunidades de actualización institucional al equipo de ciclo, departamento y claustro en su globalidad. El avance institucional se apoya en la co-reflexión compartida entre el profesorado y la búsqueda conjunta de las expectativas y problemas docentes que han de someterse a estudio y valoración rigurosa, configurando los conceptos y acciones más representativas de la vida del centro. La cultura de colaboración se asienta en la escuela cuando los docentes tienen proyectos comunes que responden a las necesidades de las comunidades y a los retos de una sociedad en continuo cambio, debiendo pensar conjuntamente las actuaciones más pertinentes para hacer avanzar la comunidad y proyectar su protagonismo en la transformación de marcos comarcales y urbanos más amplios. La práctica requiere explicitar ideas, avanzar las estrategias y evidenciar una capacidad para tomar las decisiones más oportunas en los momentos y situaciones adecuadas. La formación atenderá al dominio y replanteamiento de modelos propios para comprender la práctica y extraer de ella su sentido, a la vez que configurar la realidad educativa como un proceso de reflexión y mejora continua que incida en la actualización profesional del profesorado.

\section{MODALIDADES DE FORMACIÓN}

La formación se ha realizado, desde las diversas instituciones, Universidades, Fundaciones, CEPR, asociaciones, etc, siguiendo los planteamientos generales bien de la Administración Educativa, de las fundaciones $O$ de las expectativas del profesorado. La formación del profesorado requiere encontrar el diálogo, la ilusión y el camino según las exigencias y experiencias de mejora profesional que desde cada docente, equipos, asociaciones $\mathbf{y}$ proyectos puedan encontrarse, a la vez que hemos de descubrir las demandas sentidas desde la sociedad, los estudiantes, el Sistema Educativo y los planteamientos socio-laborales como referencia imprescindible. 
Estas demandas requieren atenderse por las instituciones y quizás desde la iniciativa insustituible de cada docente, equipo y claustro en el que trabaje. Entre las modalidades más empleadas y demandadas por el profesorado se encuentran:

- Cursos, seminarios y grupos de trabajo.

- Proyectos de innovación e investigación.

- Autoformación en Centros.

- Congresos, Jornadas, publicaciones.

- Autoanálisis de la práctica.

- Trabajos específicos de investigación, tesis, etc.

Los más valorados por el profesorado de la ESO han sido las Jornadas y los proyectos de formación en Centros, seguidos por los cursos cortos y específicos de más de 50 horas.

Estas modalidades tienen tres aspectos de incidencia complementaria: los cursos y congresos apoyan la formación en la colaboración de expertos que apoyan el proceso de actualización, bien por el dominio del tema o por su implicación y conocimiento de una práctica educativa específica. Los congresos son reuniones de rango científico que aglutinan las investigaciones de los participantes y dan al conjunto una fundamentación propia de la metodología y del rigor que ha de emplearse en este ámbito. Las restantes modalidades parten del protagonismo del profesorado, bien en la vivencia del proceso, bien en la reflexión compartida con colegas, siendo los principales responsables del diseño y desarrollo de la tarea, aunque pueden incorporarse otros investigadores, especialmente en los proyectos de innovación y afianzamiento del saber didáctico.

La formación en sus diversas modalidades pretende que el profesorado dé mayor significado y proyección a su identidad profesional y mejore su concepción y práctica educativa, preocupándose de la capacitación de los estudiantes y conviviendo en esta mejora con el mayor número de colegas.

\section{TEMPORALIZACIÓN Y LIMITACIONES DE LA REALIZACIÓN DE LA FORMACIÓN}

\footnotetext{
El tiempo que hemos de dedicar a la formación es probablemente uno de los aspectos más complejos, si se separa la formación de la práctica reflexiva, personal y en colaboración. Así, se cuestiona cuál es el momento, período y procesos que a lo largo del curso hemos de dedicar a la formación, si se ha de incidir en el dominio docente y qué tiempo es el razonable.
} 
Las respuestas dadas al proceso de formación desde las mesas redondas, se ha formulado como "el macro-problema", definiéndose como las "posibilidades reales de formación", ya que la estructura horario y los procesos de trabajo en el Centro difícilmente tienen en cuenta la necesaria reflexión compartida y los procesos de mejora profesional planteados. "Se han de encontrar tiempos y espacios comunes para dialogar y avanzar con los colegas, a fin de realizar una formación permanente de naturaleza colaborativa y apoyada en la práctica reflexiva". Se ha propuesto como los períodos más pertinentes julio o septiembre, aunque lo razonable a juicio del profesorado es "redefinir el calendario laboral incluyendo esta nueva exigencia, aprovechando las horas de permanencia y reequilibrar las actividades, posibilidades y exigencias de formación en el conjunto del horario laboral".

Si se limita una clara carrera profesional, tendría sentido recoger e integrar el propio desarrollo y la mejora continua. La actualización profesional y el proceso permanente de saber profesional debería incorporarse a un nuevo modelo de formación inicial, de aprendizaje a lo largo de la carrera docente que facilitara la implicación y el avance personal y transformador permanente. Se proyecta una línea de auto y co-desarrollo profesional autónomo y colaborativo.

Las limitaciones para el desempeño de la formación que manifiestan los entrevistados son tanto de medios como de tiempo, especialmente la dificultad de diseñar profesionalmente la línea de desarrollo desde la que se plantee el profesorado su mejora, en particular, y los claustros como equipos en general. El profesorado no siempre tiene fácil acceso a conocer todas las posibilidades de formación, aunque a veces no se promueven suficientemente desde el Centro las demandas de actualización. La excesiva dependencia de algunas modalidades de formación a los incentivos, como los sexenios, puede restar interiorización y compromiso, estando poco orientados a crear inquietudes profesionales y a satisfacer las necesidades profundas de los participantes.

Una de las limitaciones esenciales es que se desconoce la proyección real de la formación permanente realizada en los propios docentes, estudiantes, instituciones, Sistema Educativo, marco socio-laboral, transformación global de la sociedad, etc, que nos facilite las bases para mejorar la formación desarrollada.

La temporalización requiere que el profesorado, al menos bianualmente, dedique un período adecuado (de un mes a dos de actualización), que ha de continuar con la reflexión creadora desde su práctica, pensando los problemas esenciales de su vida profesional y realizando las actividades más adecuadas para que aprenda a aprender y a configurar un marco de actualización humana y profesional. Así, desde un trimestre a un semestre o año sabático, se ha de estimular la toma de conciencia personal y del claustro en la realización de una cultura de continuidad formativa. En coherencia con el proyecto global del Centro y de la comarca/ciudad se han de facilitar las modalidades y recursos más adecuados para la formación permanente. 


\section{BIBLIOGRAFÍA}

BARRIOS ARÓS, C. (1998). La formación permanente y el grupo de trabajo en el desarrollo profesional del docente en secundaria. Oikos-Tau, Barcelona.

COMISIÓN IV (1998). Evaluación de la Profesión Docente. INCE. MEC, Madrid.

ESCUDERO, J. M. (1992). "Desarrollo curricular del centro escolar: Pero... ¿qué currículum y qué centro?". Reunión desarrollo profesional basado en la escuela. Doc. Polic.

HUBER, G. (1997). Principios de la formación de formadores de adultos. Documento policopiado. Jornadas de Formación de Educadores de Personas Adultas. Madrid.

HUBER, G. y col. (1999). Finden oder suchen? (en prensa). Madrid.

MARCELO, C. (1995). Desarrollo profesional o iniciación a la enseñanza. PPU, Barcelona.

MEDINA, A. (1996). "La autobiografía. Modalidad de Formación del Profesorado: limitaciones y posibilidades". En E. López-Barajas (coord.). Historias de vida y la investigación biográfica. Fundamentos y metodología. Madrid, UNED, 95-125.

MEDINA, A. y DOMfNGUEZ, C. (1995). Enseñanza y currículum para Personas Adultas. Madrid, EDIPE, 2. ${ }^{\text {E Edic. }}$ (1998).

MEDINA, A. y DOMÍNGUEZ, M. C. (1997). "Constructing teacher practical knowledge Through classroom discourse analyse". En R. Olechowski y H. Svik (coord.). Experimental Research on Teaching and Learning. Franfurt, Peter Lang. 95-116.

MEDINA, A. y DOMÍNGUEZ, M. C. (1997). "Análisis y evaluación del conocimiento y creencias del Profesorado: La construcción del conocimiento profesional en la última década". Revista de Formación del Profesorado. E. Universitaria de Melilla.

MEDINA, A. y DOMÍNGUEZ, M. C. (1998). "Teacher' education in multicultural contexts". Lubjana, ECER, Septiembre (paper presentado).

MEDINA, A. y DOMÍNGUEZ, M. C. (1999). "El autodesarrollo profesional base de la profesionalización docente". Revista Pedagógica. Xalapa, Veracruz (en prensa).

MEDINA, A. y col. (1999). Educación y Empleo. Madrid, Ed. Learning. (en prensa).

VILLAR, L. M. (1996). "Análisis de la práctica curricular base de la formación del profesorado". Ponencia presentada al XI Congreso Nacional de Pedagogía. San Sebastián.

VILLAR, L. M. (1997). "El valor de lo marginal en el currículo y el desarrollo profesional: batutas para orquestar los elementos del caos". Conferencia Inaugural del II Congreso de Formación del Profesorado. Granada, 9-12 abril, Universidad de Granada. 


\section{RESUMEN}

La Educación Secundaria Obligatoria es la etapa innovadora del sistema educativo, al menos en su amplitud de participación y generalización del mismo a todas las personas del Estado Español, en coherencia con los nuevos retos europeos e interculturales en un mundo en constante interdependencia.

La aparición de la obligatoriedad educativa hasta los 16 años, en función de las capacidades, dedicación y aprovechamiento de los estudiantes, y adaptación del sistema coincide con la incardinación en el mismo de tres modalidades culturales relacionadas con los siguientes estilos profesionales: Maestros de Educación Básica, que acceden a impartir el primer ciclo, Profesorado de Formación profesional y Agregados y Catedráticos de Bachillerato, grupos de profesionales que asuman la responsabilidad de impartir la Educación Secundaria Obligatoria, E.S.O.

La formación actualizada de estos docentes como equipo cohesionado de desarrollo formativo en el aula, en el ciclo, en el departamento y en el Centro es probablemente la tarea más inmediata y urgente, devolviendo al profesorado el protagonismo de su formación, armonizando esta función en el Centro con cursos cortos representativos y programas especificos diseñados en colaboración por las universidades y Centros de Profesorado para comprender la complejidad de la etapa la diversidad de los estudiantes y la implicación del profesorado en la realización personal y social de todos los participantes.

La formación es la tarea transformadora más unificadora que puede asumir ella educador/ra, para desde ella replantear personalmente y en colaboración el significado de la educación, su identidad profesional, los modelos de enseñanza aprendizaje y la proyección de esta etapa en la mejora del sistema educativo en su conjunto.

Palabras clave: Formación del profesorado, educación secundaria, formación en servicio, construcción del conocimiento.

\section{ABSTRACT}

Compulsory Secondary Education is the innovative level of the Educative System, at least by its wide possibility of participation and its generalisation to all people in Spain. This new shape appears in accordance with the new European and intercultural challenges within a world of constant interdependence. 
The extension of compulsory education till 16 years old, adapted to the different students' capacities, dedication and achievement, coincides with the inclusion of three cultural modalities related to the following professional styles: Basic Eduction Teachers, who accede to impart the cycle, Professional training teachers and Baccalaureate aggregated teachers and professors, professional groups that assume the responsibility of imparting Compulsory Secondary Education (Educación Secundaria Obligatoria, ESO).

Update teachers' training as a cohesionated team of formative development within the clasroom, the cycle, the department and the centre, is perhaps, the most immediate and urgent task, that gives back to teachers the protagonism of their education. Thus, they are able to harmonise this function within the centre with representative short courses and specific programs designed in co-operation with universities and Teachers' Centres, all of them are intended to make teachers understand the complexity of the stage, the students' diversity, and their own implication in the social and self-realisation of all participants.

Teachers' training is the most transforming and unifier task that can be assumed by educators and, from this task, they can personally and in group redefine the meaning of education, their professional identity, the models of teachinglearning and the reflection of this stage on the improvement of the educative system as a whole.

Key words: Teacher education, secondary education, in-service training, knowledge construction. 